This item was submitted to Loughborough's Research Repository by the author.

Items in Figshare are protected by copyright, with all rights reserved, unless otherwise indicated.

\title{
Drilling of bone: a robust automatic method for the detection of drill bit break-
} through

PLEASE CITE THE PUBLISHED VERSION

PUBLISHER

Professional Engineering Publishing / @ IMECHE

VERSION

VoR (Version of Record)

LICENCE

CC BY-NC-ND 4.0

\section{REPOSITORY RECORD}

Ong, Fook Rhu, and Kaddour Bouazza-Marouf. 2019. "Drilling of Bone: A Robust Automatic Method for the Detection of Drill Bit Break-through". figshare. https://hdl.handle.net/2134/5148. 
This item was submitted to Loughborough's Institutional Repository (https://dspace.lboro.ac.uk/) by the author and is made available under the following Creative Commons Licence conditions.

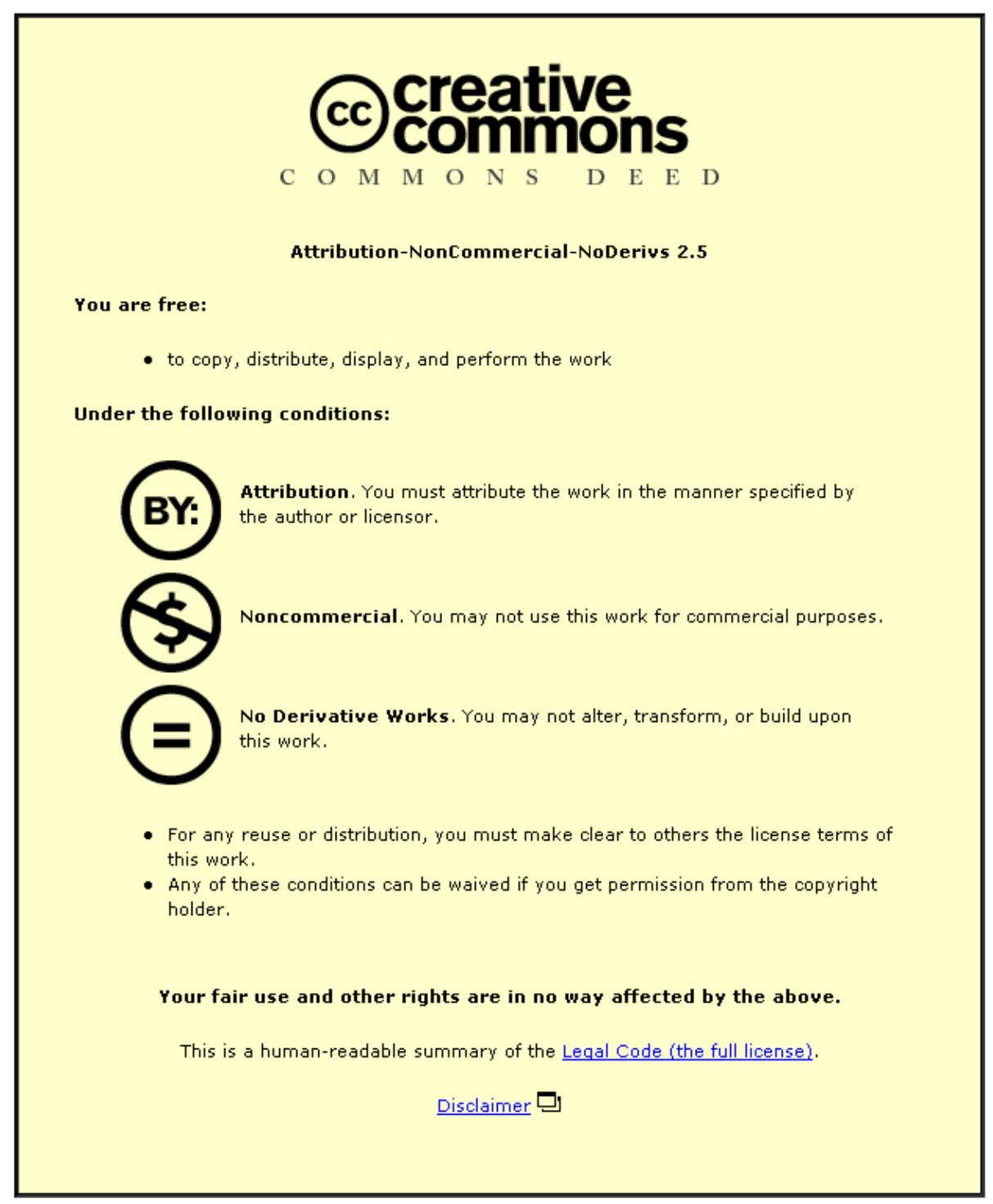

For the full text of this licence, please go to: http://creativecommons.org/licenses/by-nc-nd/2.5/ 


\title{
Drilling of bone: a robust automatic method for the detection of drill bit break-through
}

F R Ong and K Bouazza-Marouf

Department of Mechanical Engineering, Loughborough University, Loughborough, Leicestershire

\begin{abstract}
The aim of this investigation is to devise a robust detection method for drill bit breakthrough when drilling into long bones using an automated drilling system that is associated with mechatronic assisted surgery. This investigation looks into the effects of system compliance and inherent drilling force fluctuation on the profiles of drilling force, drilling force difference between successive samples and drill bit rotational speed. It is shown that these effects have significant influences on the bone drilling related profiles and thus on the detection of drill bit break-through. A robust method, based on a Kalman filter, has been proposed. Using a modified Kalman filter, it is possible to convert the profiles of drilling force difference between successive samples and/or the drill bit rotational speed into easily recognizable and more consistent profiles, allowing a robust and repeatable detection of drill bit break-through.
\end{abstract}

Keywords: bone, bone drilling, orthopaedics, mechatronic assisted surgery

\section{NOTATION}

$a$

$b$

FDSS

K-FDSS

K-Speed

$n$

$t_{\mathrm{S}}$

$t_{1}$

$t_{2}$

$x(n)$

$y(n)$

$y(n-1)$ previous estimate coefficient used in a modified Kalman filter

input/measurement coefficient used in a modified Kalman filter

force difference between successive samples Kalman processed force difference between successive samples

Kalman processed drill bit rotational speed number of samples cross-sectional thickness of femoral shaft thickness of first cortical wall of femoral shaft

thickness of second cortical wall of femoral shaft

present input/measurement used in a modified Kalman filter

present output used in a modified Kalman filter

previous output used in a modified Kalman filter

\section{INTRODUCTION}

The importance of bone drilling is reflected in two main areas of interest: orthopaedic surgery and biomechanical

The MS was received on 20 June 1997 and was accepted for publication on 12 January 1998.

H03197 @ IMechE 1998 engineering. In orthopaedic surgery, drilling of bone is extensively carried out for the fixation of fractured bones and the stabilization of spinal injuries by means of implants and screws. These techniques of fixation and stabilization, known as osteosynthesis, are less traumatic and allow for early mobilization (1), but usually involve multiple drilling operations. Biomechanical engineering looks into the drilling performance, mechanical strength of the bone and, more recently, the automation of the bone drilling process. The investigation of bone drilling performance has been targeted, in general, at the optimization of the drill bit shape and drilling conditions in order to reduce the drilling thrust force and torque, as well as the temperature generated.

The most recent development involves the automation of surgical drilling processes to take advantage of the flexibility, the accuracy and the precision offered by automated devices for the purpose of enhancing the drilling accuracy and the safety of the procedure. In addition, data such as drilling forces, displacement and rotational speed can be collected automatically during drilling operations and stored for analyses. As a result, one of such analyses can help in implementing a control algorithm to predict and to affect the outcome of a drilling procedure. One particular application of this kind is in the detection of drill bit break-through when drilling into the shaft of long bones for the fixation of shaft fractures, e.g. in the insertion of interlocking screws for intramedullary nailing. At present, this type of bone drilling procedure requires good manual skill and relies heavily 
on radiographic guidance. Break-through detection is aimed at minimizing the overtravel of the drill bit through the bone and thus reducing tissue damage caused by the rotating drill bit.

The detection of drill bit break-through has been reported by Brett et al. (2) and Allotta et al. (3), but both investigations differed in terms of break-through control strategy and bone types. Brett et al. (2) carried out drilling experiments on a stapes footplate in the middle ear, shown in Fig. 1, using a burr drill bit in accordance with the stapedectomy procedure. The stapes is a very small compliant bone in the middle ear and stapedectomy is a method of recovering loss of hearing, caused by the immobilization of the stapes, by making a hole on the stapes footplate through which a piston prosthesis is inserted to connect the incus to the inner ear. In the experiments, both the force and the torque along with the displacement of the drill bit were measured using a feed rate in the range of $0.2-1.0 \mathrm{~mm} / \mathrm{min}$ and a drill speed of $120 \mathrm{r} / \mathrm{min}$. A $0.6 \mathrm{~mm}$ diameter burr drill bit was used. At the start of drilling, both the force and the torque increase steadily as a result of the advance rate being greater than the penetration rate; this causes the stapes footplate to deflect. On the verge of breakthrough, there is a gradual fall in force, which is followed by a rapid fall in force and a rapid increase in torque. The characteristics of the force and torque associated with the break-through process are shown to be always present when drilling a stapes footplate. Only the magnitudes of maximum force and torque vary with the stiffness of the stapes, drill feed velocity and drill bit sharpness. These bit force and torque characteristics are then applied to the automatic detection of break-through by identifying the persistent increase in the torque over six sample periods while the force decreases. When this condition, which occurs before bit break-through, is true, the drill rotation is stopped and the drill bit is retracted until a zero feed force is obtained. At this point, the stapes footplate returns to the original position. Subsequently, a second advance of the drill bit is initiated to achieve a fully formed hole with minimum

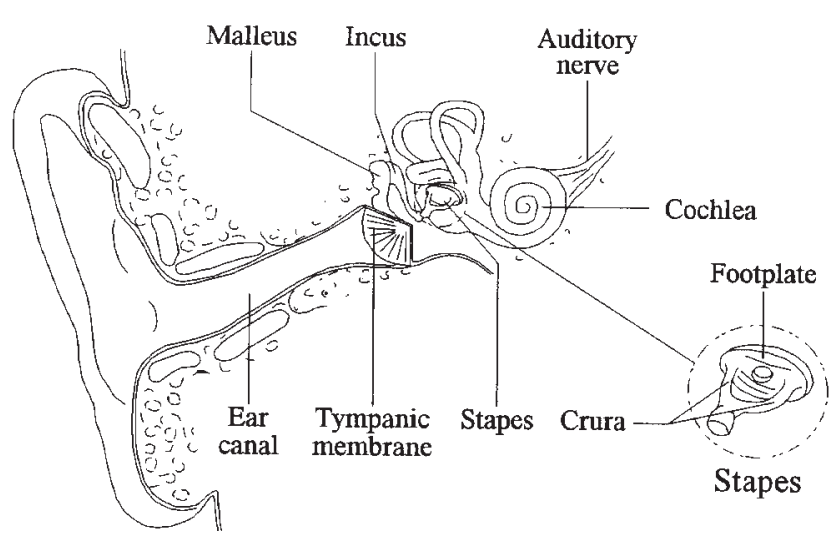

Fig. 1 The middle regions of the ear bit protrusion. The peak force in the second drilling phase is lower than the first, while the peak torque is higher due to the decreased deflection of the stapes footplate.

A different drill bit break-through detection method was proposed by Allotta et al. (3) as part of a mechatronic tool design for drilling in orthopaedics. The experiments were conducted on porcine femoral shafts using a d.c. motor powered drill prototype mounted on a testing machine and a standard metal drill bit of diameter $3.5 \mathrm{~mm}$. Both the force and torque were measured under feed rates of 50,75 and $100 \mathrm{~mm} / \mathrm{min}$, and rotational speeds of 1500,1800 and $2000 \mathrm{r} / \mathrm{min}$. There are two prominent peak forces at the two cortical walls with sharp changes on entry and on exit of the bone. Using a force derivative algorithm, these sharp changes are detected and, with appropriate thresholds, the onset of bit break-through is identified. Theoretical models of the drilling thrust force and break-through force profile were shown to compare well with the experimental data. However, fixed thresholds cannot be used since the forces, and their derivatives, are functions of the drill bit diameter, feed rate and cutting speed. In addition, the effect of the system compliance related to the support of the bone was not taken into account, as a stiff system was used.

\section{EFFECTS OF SYSTEM COMPLIANCE AND DRILLING FORCE FLUCTUATION}

The detection methods of drill bit break-through proposed by Brett et al. (2) and Allotta et al. (3) work well when the bone involved has a relatively even structural density. Bone itself is a porous non-homogeneous material and therefore both the drilling force and the torque are affected by the changes in bone structural density. Furthermore, the effects of system compliance have an element of uncertainty and will add to the difficulty of devising a robust method of break-through detection.

Figure 2 shows the effects of compliance on the drilling force profiles across a porcine femoral shaft. Drilling under the influence of low stiffness (high compliance) is shown to require a larger drill bit displacement to complete the hole. Moreover, the characteristics of the two force profiles (with and without system compliance) differ significantly from each other for both the first and second cortical walls. The force drops to zero in the medullary section.

The effect of inherent drilling force fluctuation, generally caused by changes in the bone structural density, on the drilling force profile is shown in Fig. 3 for a stiff system. This figure also includes the profile of force difference between successive samples (FDSS), which is similar to the force derivative based on backward difference. Of interest is the force profile of the second cortical wall, where there are often multiple peaks and troughs. 


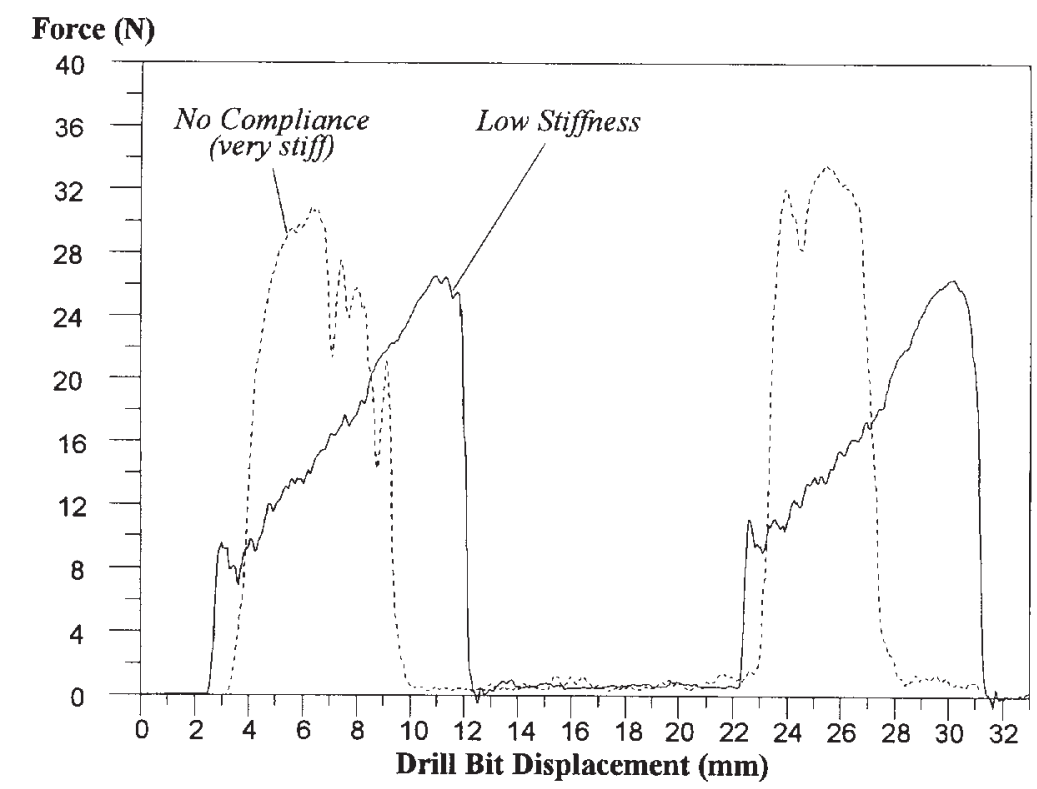

Fig. 2 Drilling force profiles of porcine femoral shafts with and without system compliance

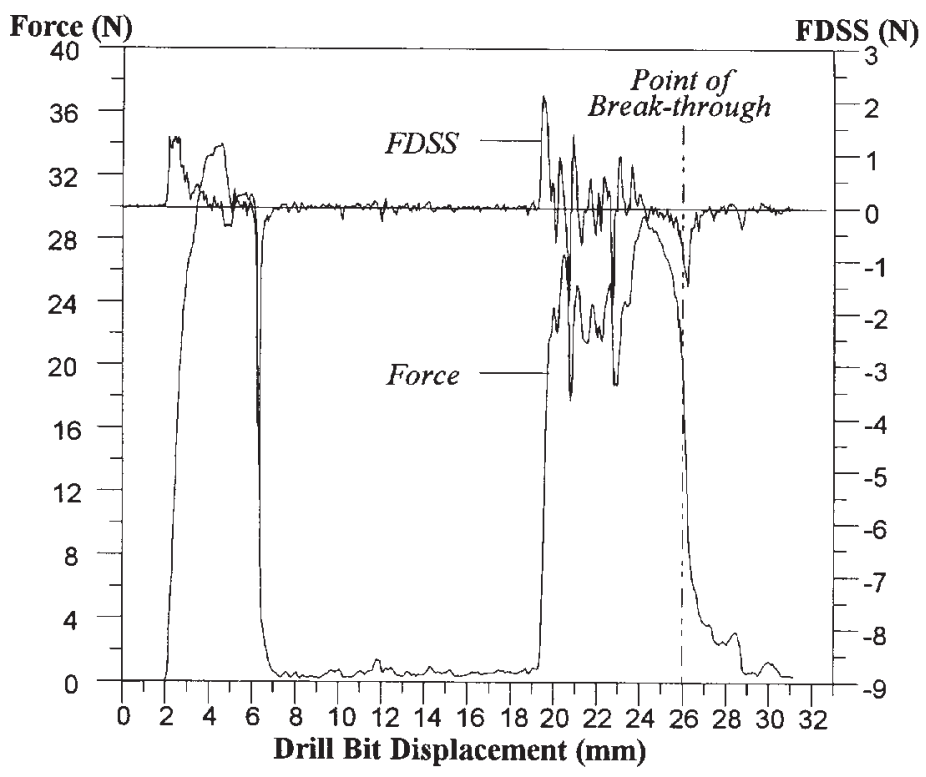

Fig. 3 Drilling force and force difference between successive samples (FDSS) profiles of a porcine femoral shaft affected by inherent force fluctuation (stiff system)

As a result, false break-through characteristics, from these sharp changes, are detected when a force derivative function with a fixed threshold is used. In addition, the thresholding technique related to the derivative function can only be implemented after drill bit break-through has occurred. Further analyses and discussions of system compliance and inherent drilling force fluctuation effects are presented in the following sections.

The aim of this investigation is to develop a robust method of break-through detection regardless of system compliance and inherent drilling force fluctuation when drilling into long bones. The detection method for long bones proposed by Allotta et al. (3) does not take system compliance and drilling force fluctuation effects into consideration. The purpose of introducing system compliance is to simulate conditions as close to the actual clinical condition as possible. In actual surgical procedures it is extremely difficult to fix the specific part of the anatomy rigidly, and hence system compliance is always present.

The method proposed in this paper for the detection of drill bit break-through is based on a Kalman filter (4) applied to the force difference between successive samples (FDSS) and to the rotational drill speed data. The Kalman filter is a digital linear time-varying estimator designed to remove random fluctuations and to 
establish long-term trends by smoothing any sudden or abrupt changes in the input. In the proposed drill bit break-through detection method, a modified Kalman filter in the form of an elementary first-order low-pass recursive filter is applied. The modified filter is given by

$$
y(n)=a y(n-1)+b x(n)
$$

where $n$ is the number of samples, $a$ and $b$ are constants, $x(n)$ is either the FDSS or the drill bit rotational speed and $y(n)$ is the output of the filter. The constants $a$ and $b$ are subjected to a constraint represented by $a+b<1$ to ensure that the filter remains stable. These two constants, $a$ and $b$, have been chosen as 0.99 and 0.009 respectively. Thus the filter used is given by

$$
y(n)=0.99 y(n-1)+0.009 x(n)
$$

It can be seen that this filter has a very small weighting of the input so that sufficient time is given to smooth out abrupt changes and establish the input trends. Since the force profiles, as shown in Fig. 2, have typical characteristics of sudden changes on entry and exit of the bone, a trend on these changes can be ascertained regardless of any fluctuations of the peaks in the profiles.

\section{EXPERIMENTAL METHOD}

All the experiments were carried out on a drilling rig which consists of a compliant bone holder, a drill feed unit, a bidirectional force sensor, a quick mount drill holder and a speed sensor, as shown in Fig. 4. This drilling rig is part of an experimental system used in the ongoing research project on mechatronic assistance in orthopaedic surgery (5). The bone holder clamps the bone to be drilled at the top and introduces the compliance in a controlled manner using compression springs of various coefficients of stiffness. The drill feed unit provides a constant feed rate through a ball screw driven by a stepper motor, and measures the feed displacement through a linear potentiometer. The drilling force measurement is obtained from the change in resistance of strain gauges in the Wheatstone configuration on a cantilever plate. The analogue measurements are filtered, using fourth-order analogue Butterworth filters, to reduce/eliminate noise and avoid aliasing. An air drill is mounted on the drill holder which incorporates a drill bit guide. The drill bit guide prevents long drill bits from deflecting in order to maintain the desired drilling trajectory. The use of the air drill complies with current practice in orthopaedic surgery and, for experimental purposes, industrial air drills at rated rotational speeds of 3300, 1900 and $1000 \mathrm{r} / \mathrm{min}$ have been used. The rated rotational speed of $1000 \mathrm{r} / \mathrm{min}$ is within the range of speeds produced by surgical air drills. The higher rotational speeds have been tested as it may be possible to use these higher speeds with automated drilling. Both surgical and industrial drill bits have been used in the experiments. The drill holder is designed to withstand sterilization by steam (autoclaving) which is easily available and relatively inexpensive. Finally, the drill bit rotational speed sensor consists of a digital reader and a rotary encoder disc which is fixed near the drill chuck along the drill bit shank.

The relationship between drilling force and torque is well established in the literature (6-9). However, torque measurements are either derived from electrical motor current or obtained from a dynamometer mounted on a lathe or a drilling machine. In this experimental setting, torque measurement is not implemented. Instead, changes in torsional resistance of the bone are taken to be represented by changes in the rotational speed of the drill.

Drilling experiments were performed on the cortical bone along the middle section of fresh porcine femoral shafts (diaphysis), as shown in Fig. 5. As in human long bones, the medullary cavity, which is filled with soft

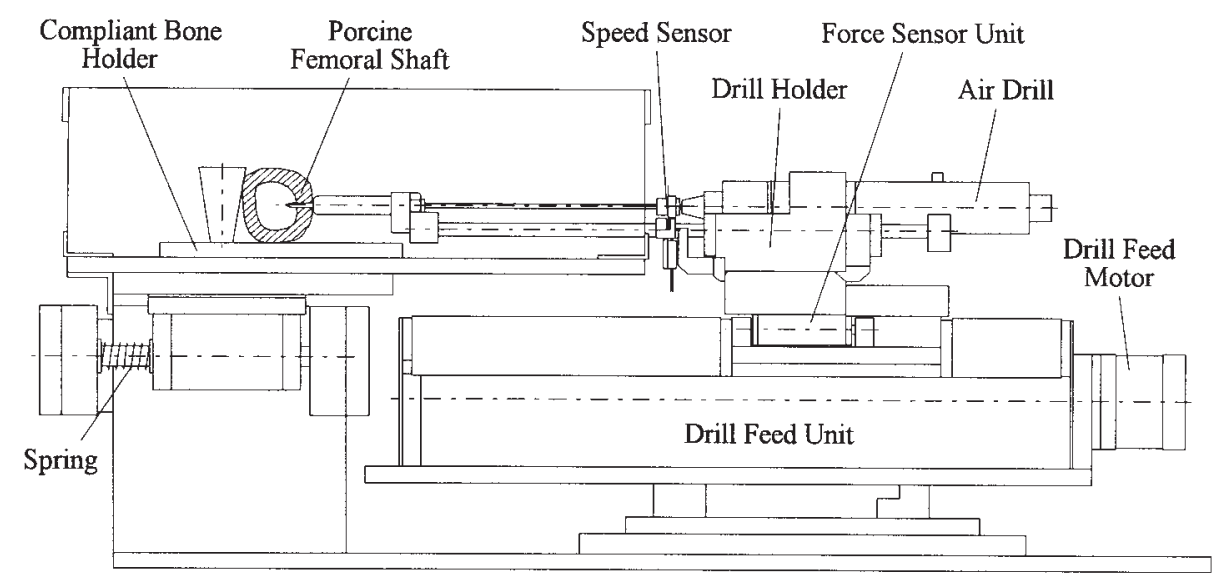

Fig. 4 Experimental set-up for drilling porcine femoral shafts 

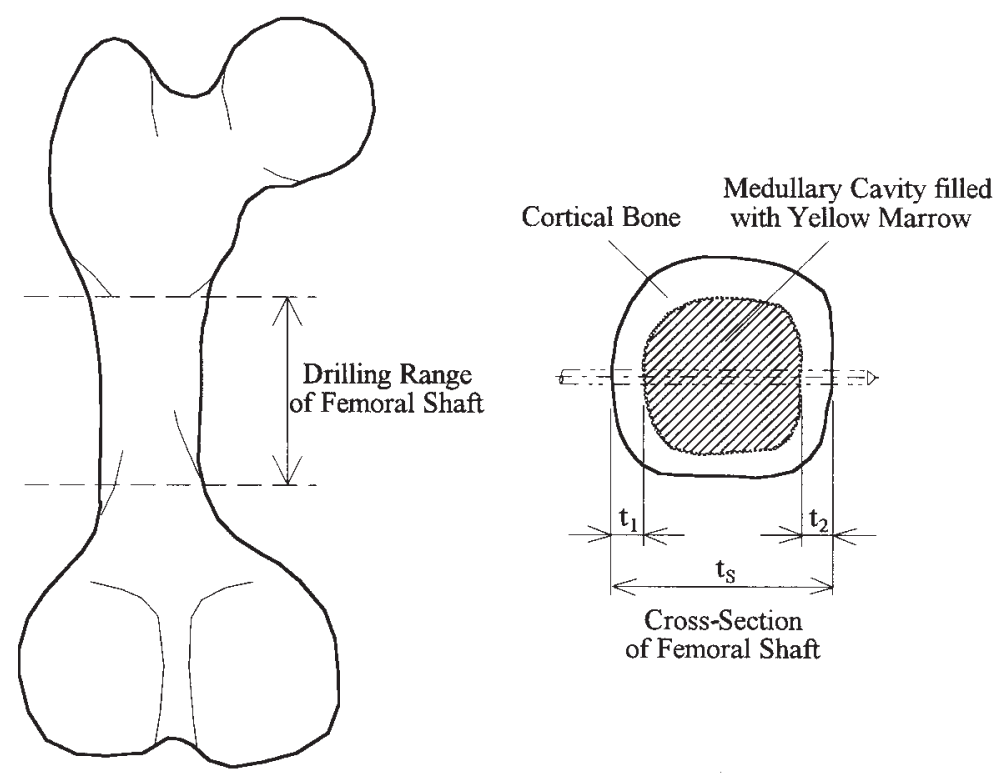

Fig. 5 Drilling range and cross-section of a porcine femur

yellow marrow, is surrounded by cortical bone. The thickness of the first and second cortical walls are indicated by $t_{1}$ and $t_{2}$ respectively, while the cross-sectional thickness of the femoral shaft is indicated by $t_{\mathrm{s}}$. The whole femur was clamped rigidly on to the bone holder to ensure that the system compliance was only caused by the spring used in the 'compliant bone holder'. It must be noted that there is a negligible compliance caused by the deflection of the force sensor's cantilever plate. Three springs with stiffness coefficients of 2.80 , 5.68 and $10.90 \mathrm{~N} / \mathrm{mm}$ were used to vary the system compliance. The drill bit, a standard metal cutting type, of diameter $2.5 \mathrm{~mm}$, was driven at a feed rate of $132 \mathrm{~mm} / \mathrm{min}$

\section{RESULTS}

The measured results were drill feed displacement, drilling thrust force and rotational speed of the drill bit, while the processed data through the modified Kalman filter involved the force difference between successive samples and the rotational speed. In addition, the speed data were processed through a digital second-order filter. All the data involving force and speed were plotted against the drill feed displacement.

Figure 6 shows experimental results of drilling force and drill bit rotational speed for different compliance values; spring stiffness coefficients of $2.80,5.68$ and $10.90 \mathrm{~N} / \mathrm{mm}$ were used. The values in brackets represent actual bone measurements (as indicated in Fig. 5), while the values not in brackets represent the actual drill bit displacement. As expected, the results show that the force and the speed profiles are significantly affected by the compliance of the bone holder. Figure 6a shows typical force and speed profiles for a stiffness coefficient of $2.80 \mathrm{~N} / \mathrm{mm}$. The force increases quite rapidly as the drill bit penetrates the cortical bone; then the increment becomes more gradual in a series of steps, while the speed decreases gradually. Around the maximum value, the force becomes relatively constant and the speed is at its lowest immediately before break-through. Upon break-through, the force drops sharply to zero at the interface of the cortical bone and the medullary cavity, while the speed recovers. Unlike a very stiff system, there is a large difference between the feed displacement and the bone cross-section measurement, especially in the first cortical wall, along the drill bit path. This is due to the system compliance. For example, a feed displacement of $9.5 \mathrm{~mm}$ is exhibited in the first cortical wall of thickness $4.4 \mathrm{~mm}$, while a feed displacement of $8.0 \mathrm{~mm}$ instead of $12.6 \mathrm{~mm}$ is exhibited in the medullary section.

The force profile, in Fig. 6b, for a stiffness coefficient of $5.68 \mathrm{~N} / \mathrm{mm}$ shows a higher initial penetration force before a shorter series of steps in the rise of force. The maximum value of the drilling force is approximately 20 per cent higher than for the system with a spring stiffness coefficient of $2.80 \mathrm{~N} / \mathrm{mm}$. A typical sharp drop is shown upon break-through, and the rotational speed profile is similar to that of the system with higher compliance, but with a higher slope. As expected, a very small difference between the feed and penetration displacements is indicated.

Figure $6 \mathrm{c}$ shows the experimental results at a higher stiffness coefficient of $10.90 \mathrm{~N} / \mathrm{mm}$. The drilling force has a sharper rise and a higher maximum value, which is approximately 50 and 20 per cent higher than the systems with spring stiffnesses of 2.80 and $5.68 \mathrm{~N} / \mathrm{mm}$ 


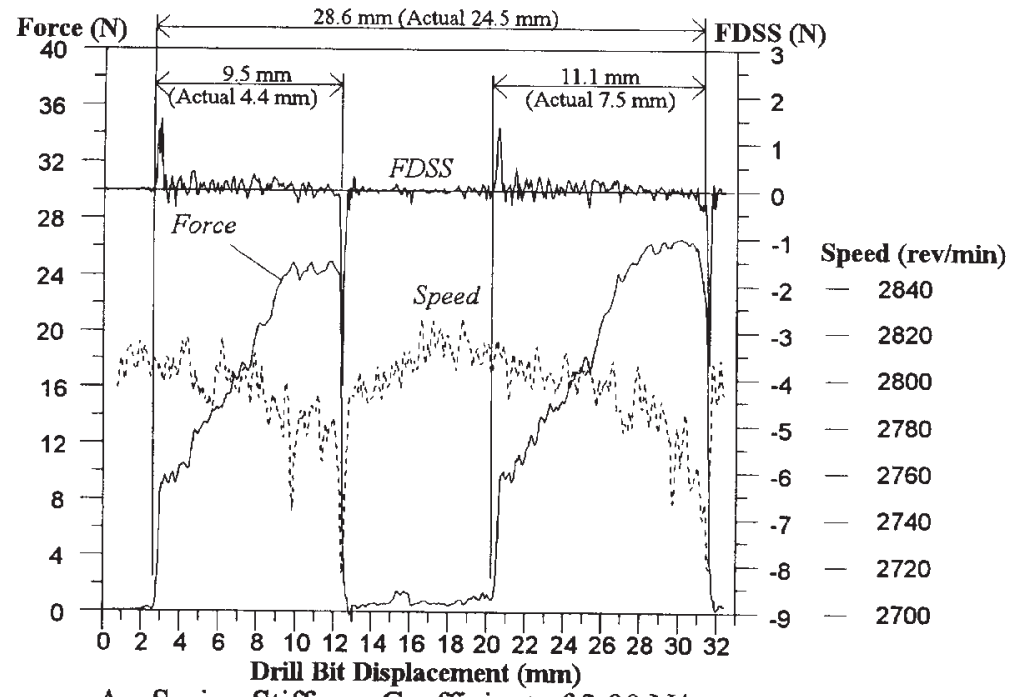

A - Spring Stiffness Coefficient of $2.80 \mathrm{~N} / \mathrm{mm}$

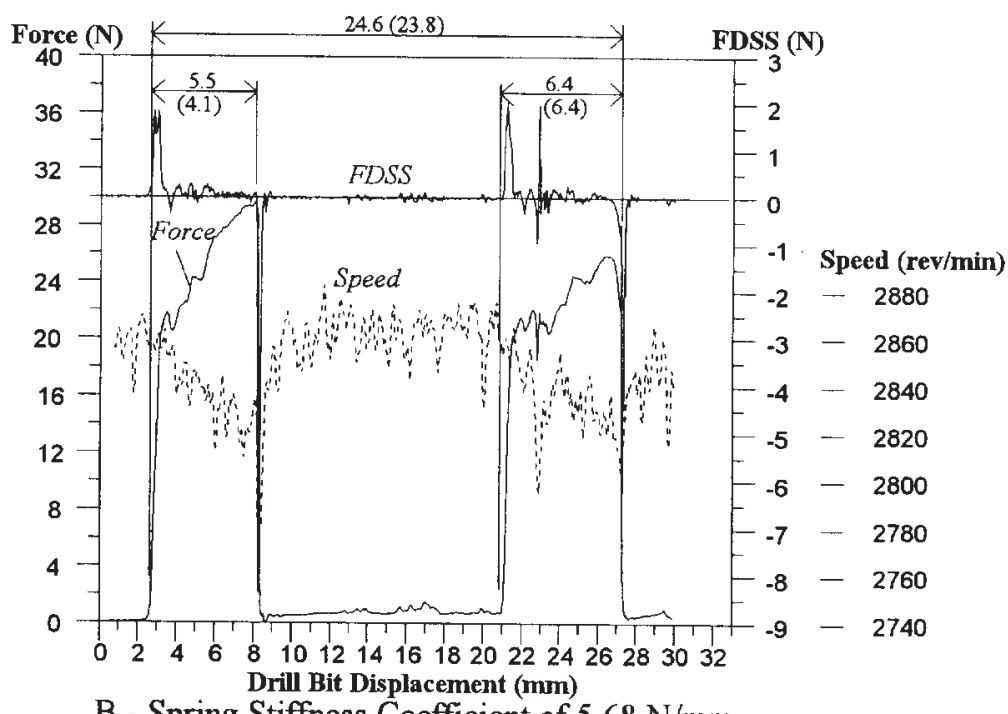

B - Spring Stiffness Coefficient of $5.68 \mathrm{~N} / \mathrm{mm}$

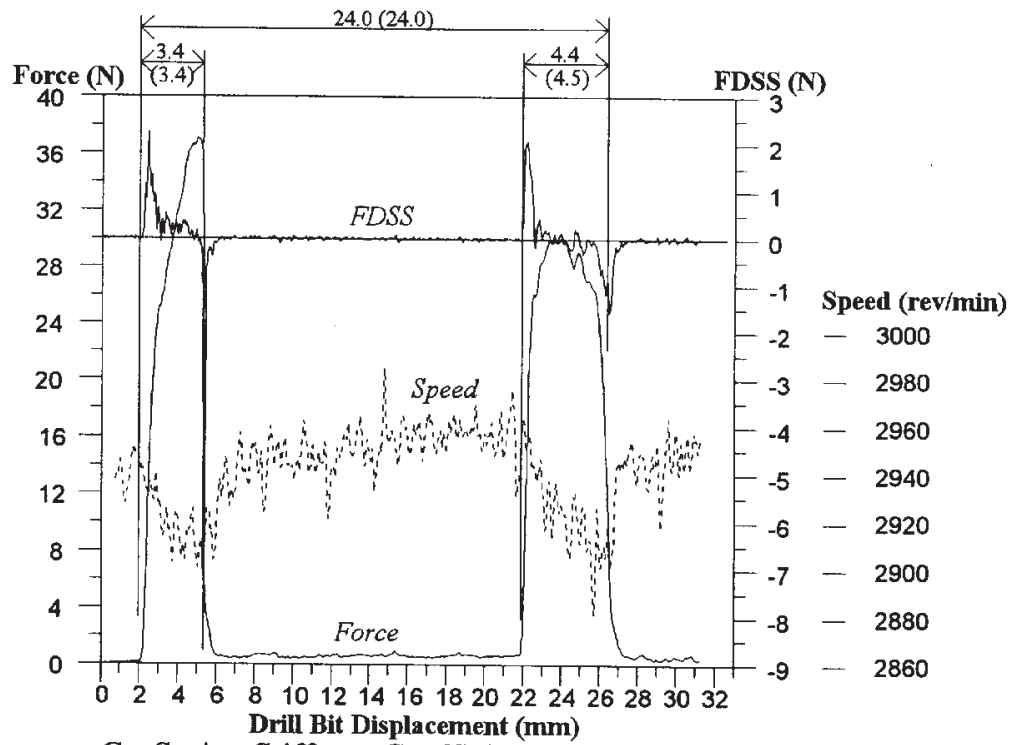

\section{C - Spring Stiffness Coefficient of $10.90 \mathrm{~N} / \mathrm{mm}$}

Fig. 6 Profiles of drilling force, force difference between successive samples (FDSS) and rotational speed for a porcine femoral shaft with system compliance (feed rate $=132 \mathrm{~mm} / \mathrm{min}$; rated speed $=3300 \mathrm{r} / \mathrm{min}$ ) 
respectively. In contrast to the systems with high compliance, and as expected, there is hardly any difference between the feed and penetration displacements. There is, however, a noticeable difference in the maximum drilling force in the two cortical walls. This could be attributed to the difference in the structural density or strength between the two walls.

A force difference between successive samples (FDSS) profile is shown for each stiffness condition in Fig. 6. A sharp change is recorded as the drill bit enters and breaks through each cortical wall. However, when the breakthrough is gentler, as seen in Fig. 6c in the second cortical wall, the FDSS becomes smaller; this could cause a delay in the detection of break-through. As for the use of drill bit rotational speed for break-through detection, there are many fluctuations in the speed measurements, which makes break-through very difficult to detect.

When compared to the results processed through the modified Kalman filter, different trends of force difference and rotational speed are obtained, as shown in Fig. 7. The Kalman processed force difference between successive samples (K-FDSS) trends, for the three stiffness conditions, show different characteristics. However, a common feature is that the K-FDSS increases when the drill bit penetrates the bone and drops rapidly during break-through; a K-FDSS of $0.00 \mathrm{~N}$ is shown at the beginning of break-through in both the first and second cortical walls. Therefore, a break-through dectection can be established by monitoring when the K-FDSS drops to zero. An earlier break-through detection is also possible by setting a higher threshold. For instance, a higher K-FDSS threshold of $0.03 \mathrm{~N}$, as shown by the horizontal dashed lines in Fig. 7, provides an early indication of the commencement of drill bit break-through for all three system stiffness conditions.

The Kalman processed rotational speed (K-Speed) has similar trends for the three stiffness conditions, as shown in Fig. 7. The K-Speed increases steadily to a maximum value around the entry to the second cortical wall before dropping steadily. The K-Speed increases again soon after the drill bit break-through. Also, the fluctuations of the measured speed (seen in Fig. 6) have little influence on the Kalman processed data. This type of characteristic makes it possible to implement drill bit rotational speed for the detection of break-through. A threshold based on a ratio or percentage of the maximum K-Speed could be used to monitor break-through. For example, taking 99.3 per cent of the maximum K-Speed in each stiffness condition, as shown by the horizontal dash-dot lines in Fig. 7, makes earlier break-through detection possible.

Figure 8 shows the effect of inherent force fluctuation on the force profile, the K-FDSS and the K-Speed. Sharp changes are shown for the force. The break-through detection method based on a force derivative with a fixed threshold is especially prone to these changes, which are thus the main cause of failure of the break-through detection technique suggested by Allotta et al. (3). However, using a Kalman filter, a trend is shown to be present for the profiles of the K-FDSS and K-Speed. As mentioned earlier, with appropriate thresholds the commencement of drill bit break-through could be established well in advance. Using the same previous thresholds of $0.03 \mathrm{~N}$ for the K-FDSS and 99.3 per cent of the maximum K-Speed, the drill bit break-through is detected before it takes place.

The application of the K-FDSS as the primary algorithm for the detection of break-through is a robust method since break-through occurs when the K-FDSS drops to zero (in either the first or second cortical walls); this is clearly indicated in Figs 7 and 8. It must be noted that an earlier detection of break-through, using the $\mathrm{K}-\mathrm{FDSS}$, is also possible if a higher threshold, say $0.03 \mathrm{~N}$, is set. The use of the K-Speed complements the K-FDSS and improves the reliability of the proposed break-through detection method. To demonstrate the versatility of this detection method, similar results were obtained from experimental tests at different feed rates and drill bit rotational speeds. Figures 9 and 10 show the profiles of drilling force, K-FDSS and K-Speed for a feed rate of $90 \mathrm{~mm} / \mathrm{min}$ at rated rotational speeds of 1900 and $1000 \mathrm{r} / \mathrm{min}$ respectively. With the same earlier threshold setting of $0.03 \mathrm{~N}$ for the K-FDSS, this method gives an indication of imminent drill bit break-through for both rotational speeds. In contrast, the performance of the K-Speed in break-through detection is not as favourable at low rotational speeds, as shown in Fig. 10 for a speed of $1000 \mathrm{r} / \mathrm{min}$. The reason for this may be the difficulty in detecting the change of rotational speed at low rotational speeds. Therefore, a higher value of threshold setting than 99.3 per cent of the maximum K-Speed may be required. At a higher rotational speed of $1900 \mathrm{r} / \mathrm{min}$ (Fig. 9), the same threshold setting of 99.3 per cent of the maximum K-Speed applies for the advance detection of break-through.

Since the previous analyses are based on an industrial drill bit, additional experimental tests have been carried out using a surgical drill bit of the same diameter $(2.5 \mathrm{~mm})$ to verify the proposed technique, using a modified Kalman filter, in identifying the imminence of drill bit break-through. The surgical drill bit was driven at a feed rate of $90 \mathrm{~mm} / \mathrm{min}$ and a rated rotational speed of $1000 \mathrm{r} / \mathrm{min}$. This rotational speed is within the range of speeds generated by surgical air drills. The breakthrough characteristics of a surgical drill bit represented by the K-FDSS and the K-Speed, as shown in Fig. 11, have been found to have similar patterns to those of a metal cutting drill bit. However, the magnitudes of the maximum drilling force are generally lower as the surgical drill bit is specifically designed for use on bones. With the same threshold setting of $0.03 \mathrm{~N}$, the K-FDSS successfully identifies the imminent drill bit break-through. The performance of the K-Speed, as expected, is not as favourable, especially at low rotational speeds, and 


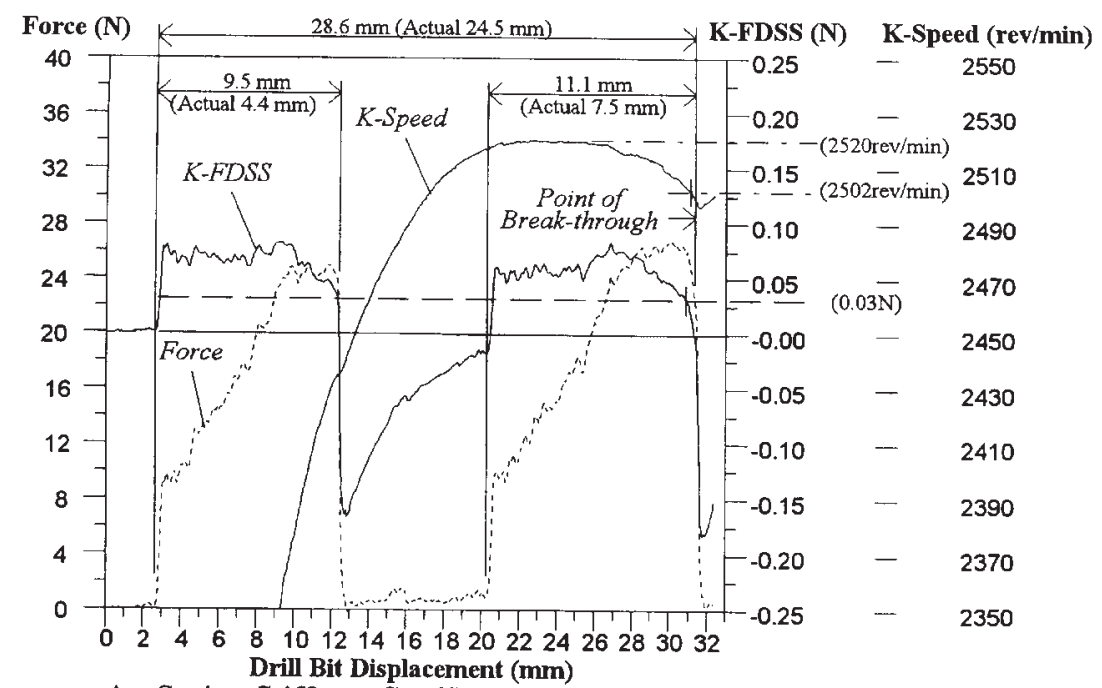

A - Spring Stiffness Coefficient of $2.80 \mathrm{~N} / \mathrm{mm}$

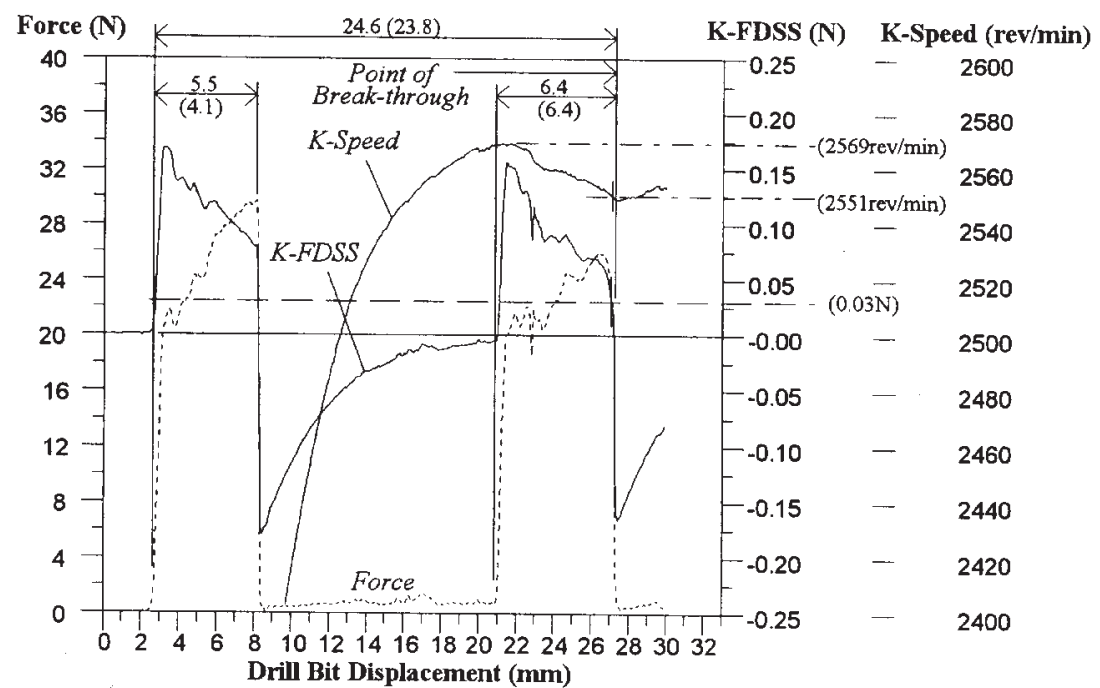

B - Spring Stiffness Coefficient of $5.68 \mathrm{~N} / \mathrm{mm}$

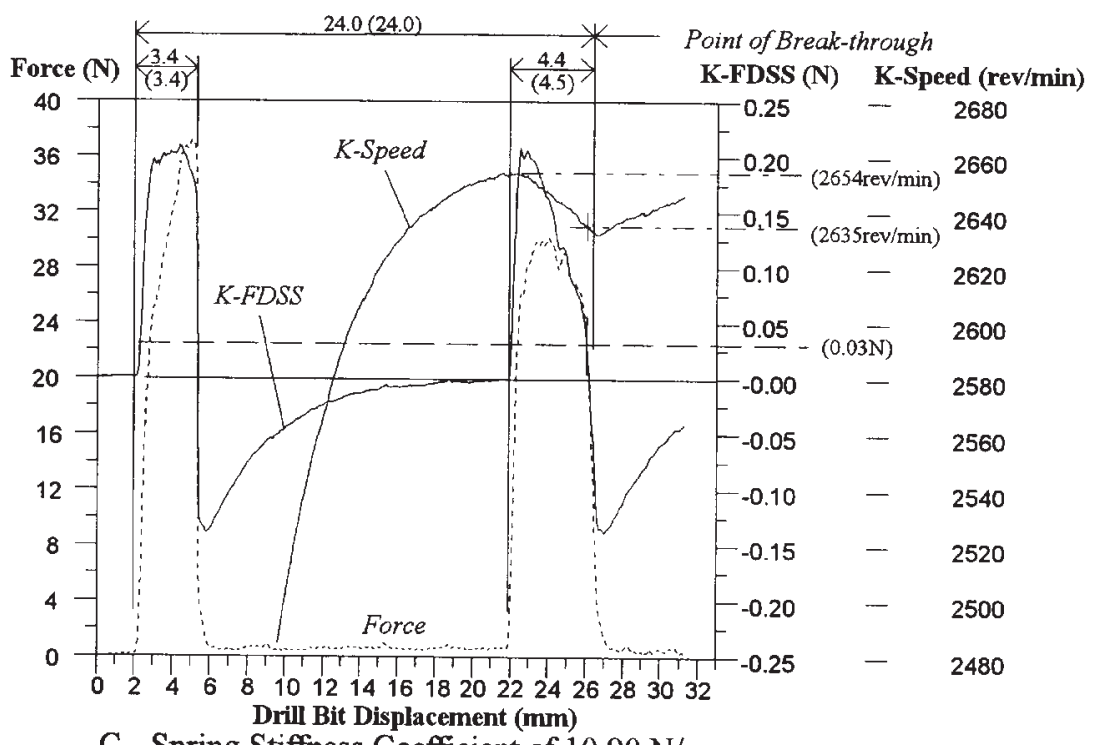

C - Spring Stiffness Coefficient of $10.90 \mathrm{~N} / \mathrm{mm}$

Fig. 7 Profiles of drilling force, processed Kalman FDSS (K-FDSS) and processed Kalman rotational speed (K-Speed) for a porcine femoral shaft with system compliance (feed rate $=132 \mathrm{~mm} / \mathrm{min}$; rated speed $=$ $3300 \mathrm{r} / \mathrm{min}$ ) 


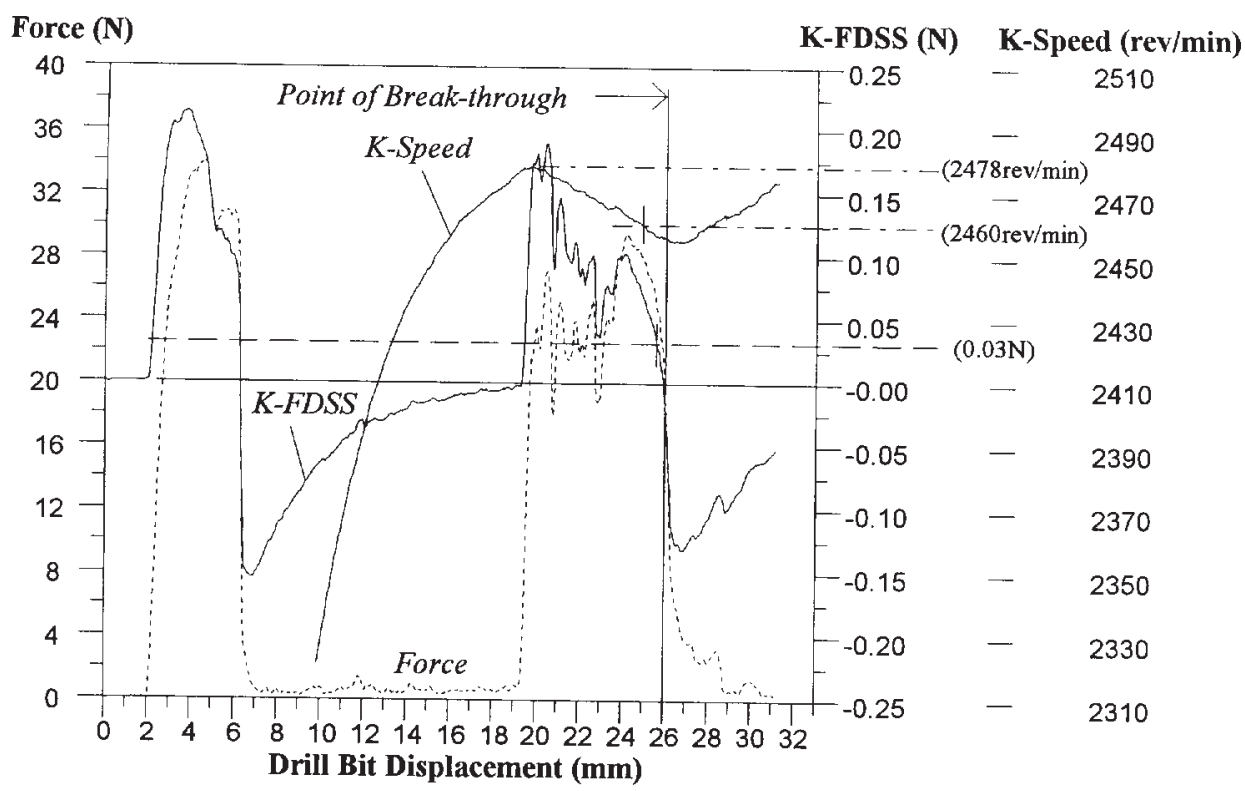

Fig. 8 Profiles of drilling force, processed Kalman FDSS (K-FDSS) and processed Kalman rotational speed (K-Speed) for a porcine femoral shaft affected by inherent force fluctuation of a stiff system (feed rate $=132 \mathrm{~mm} / \mathrm{min}$; rated speed $=3300 \mathrm{r} / \mathrm{min}$ )

hence a higher value of threshold than 99.3 per cent of the maximum K-Speed may be required. Nevertheless, the Kalman algorithm has been shown to be suitable for use on the surgical drill bit in predicting the imminent drill bit break-through.

\section{DISCUSSION}

In bone, or other materials, the drilling force profile depends on the penetration rate, as well as on other factors such as drill bit geometry, drill bit sharpness and rotational speed. The penetration rate is directly dependent on the drill bit feed rate and on the stiffness of the system. System compliance has the effect of reducing the penetration rate and thus results in low drilling force magnitudes. However, at low stiffness (i.e. high compliance) there is a springback effect as soon as breakthrough occurs. This may result in excessive penetration and thus tissue damage. An early and robust detection of break-through is therefore necessary. It has been shown that break-through detection using the force derivative with a fixed threshold may fail because there are sharp changes in the force profile that could give a false indication of break-through. In addition, this method results in a later detection of break-through which may be too late to stop excessive penetration of the drill bit. The problems related to the force derivative with the fixed threshold method can be overcome by incorporating a modified Kalman filter and applying it to either (or both) the drilling force difference between successive samples or (and) the drill bit rotational speed.

The proposed method, the application of Kalman filter to both drilling force difference and drill bit rotational speed data, has produced a simple, robust and repeatable technique of detecting drill bit break-through in the second cortical wall. Although drilling force difference and drill bit rotational speed profiles are greatly affected by system compliance, using a Kalman filter it is possible to convert these profiles into easily recognizable and more consistent profiles despite the inherent fluctuation present in the drilling force and the drill bit rotational speed measurements. The Kalman filter irons out major fluctuations and creates a trend that can easily and safely be implemented in real time in break-through detection algorithms.

It can be concluded that the detection of drill bit break-through, when drilling into long bones, using the proposed Kalman filter processed profiles of drilling force difference and drill bit rotational speed is robust and repeatable. This technique can be implemented in real time into automated drilling systems for the detection of drill bit break-through.

\section{ACKNOWLEDGEMENT}

This investigation was partly supported by the Wishbone Trust of the British Orthopaedic Association. The authors are grateful for the financial support provided. 


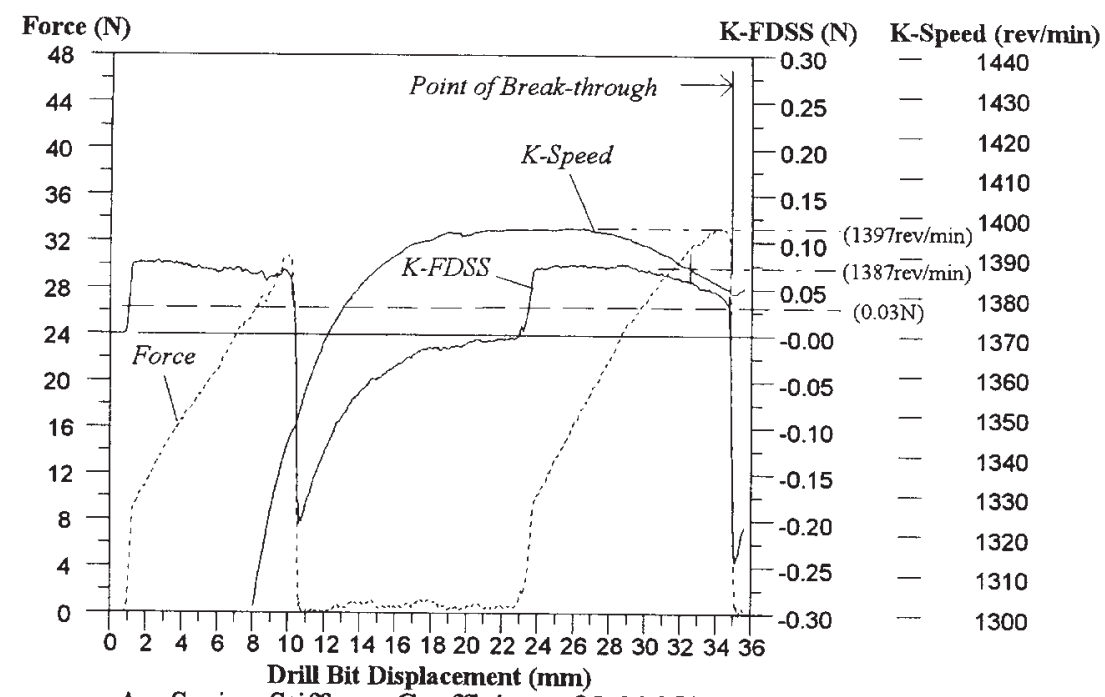

A - Spring Stiffness Coefficient of $2.80 \mathrm{~N} / \mathrm{mm}$

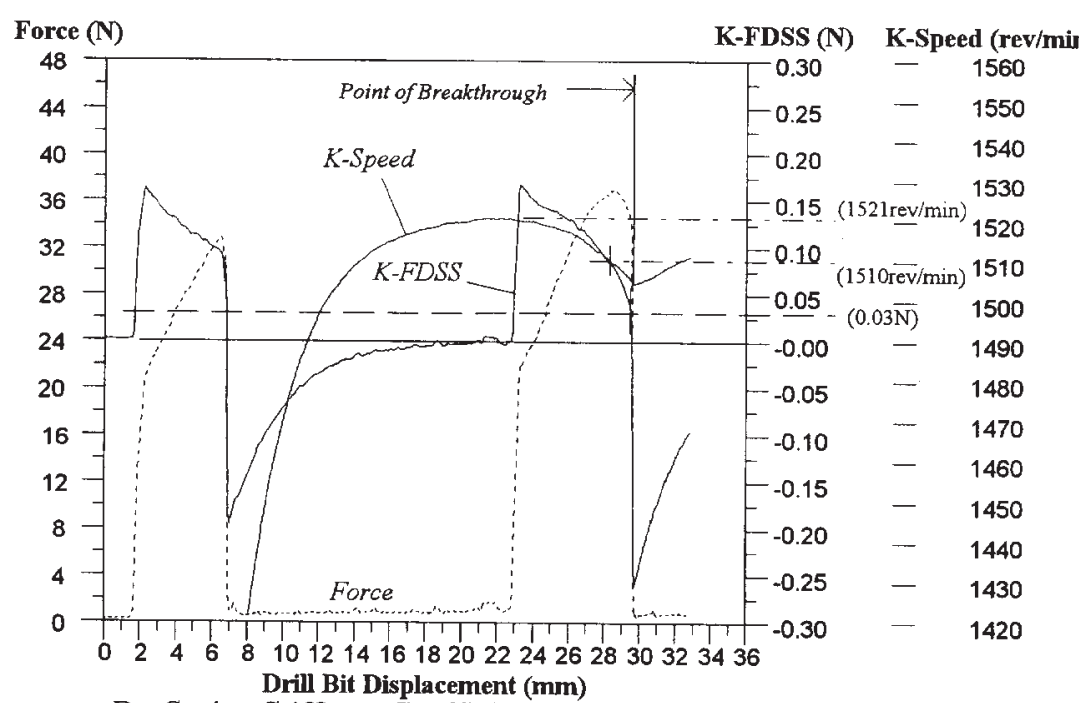

B - Spring Stiffness Coefficient of $5.68 \mathrm{~N} / \mathrm{mm}$

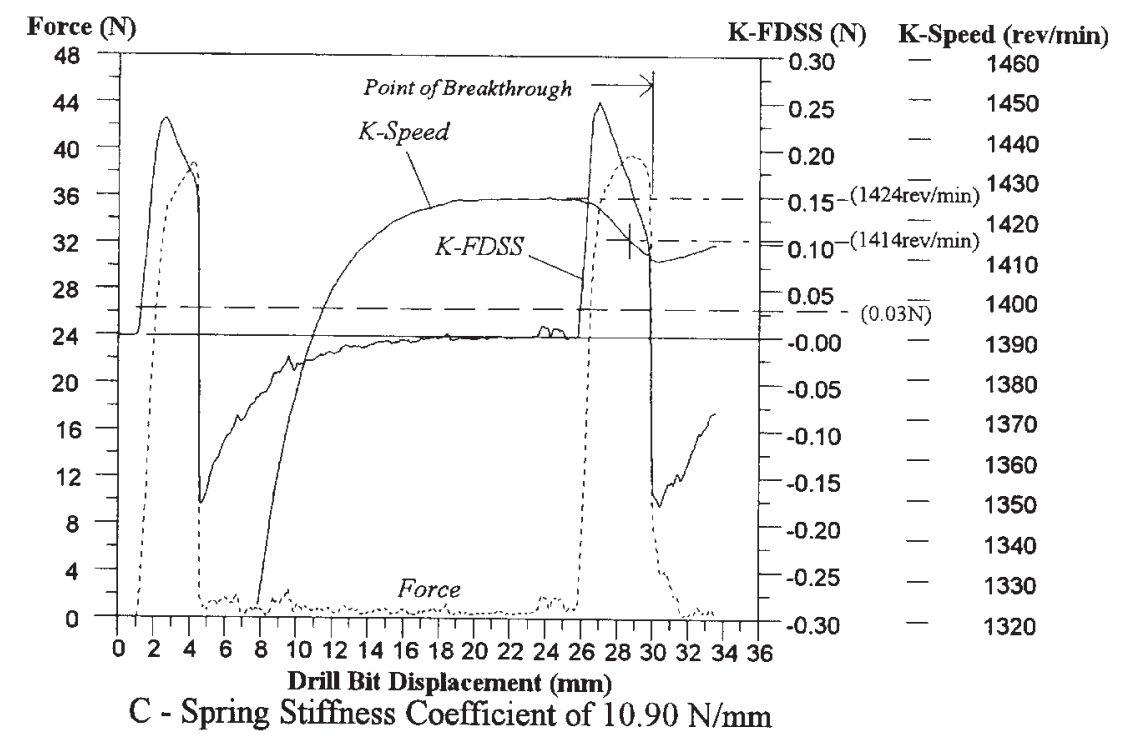

Fig. 9 Profiles of drilling force, processed Kalman FDSS (K-FDSS) and processed Kalman rotational speed (K-Speed) for a porcine femoral shaft with system compliance (feed rate $=90 \mathrm{~mm} / \mathrm{min}$; rated speed $=$ $1900 \mathrm{r} / \mathrm{min}$ ) 


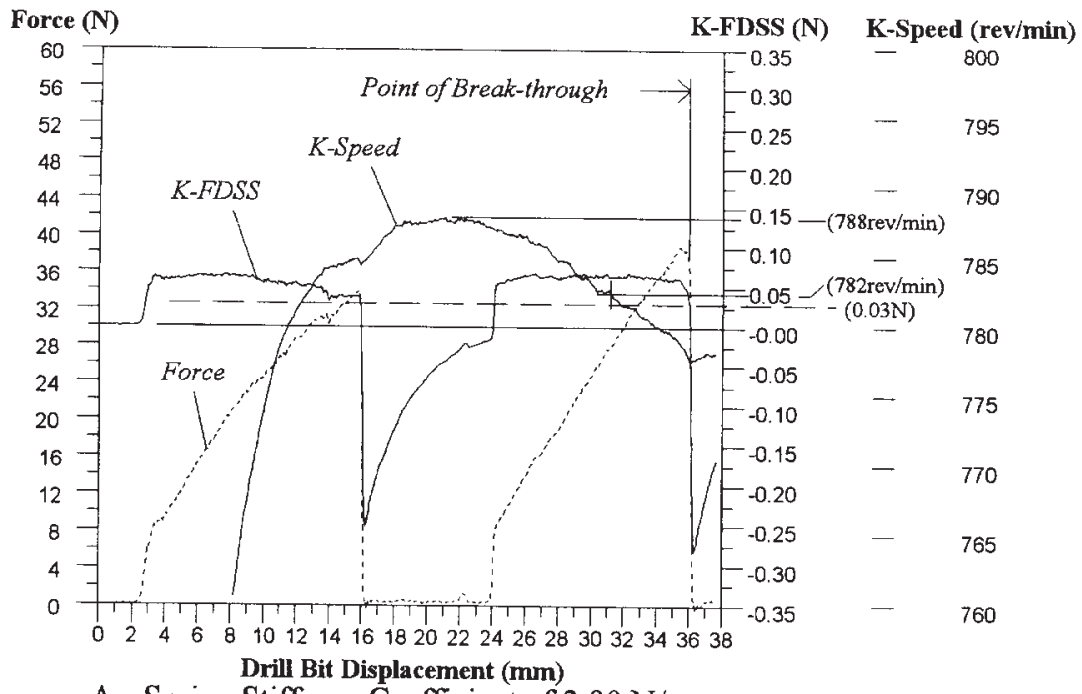

A - Spring Stiffness Coefficient of $2.80 \mathrm{~N} / \mathrm{mm}$
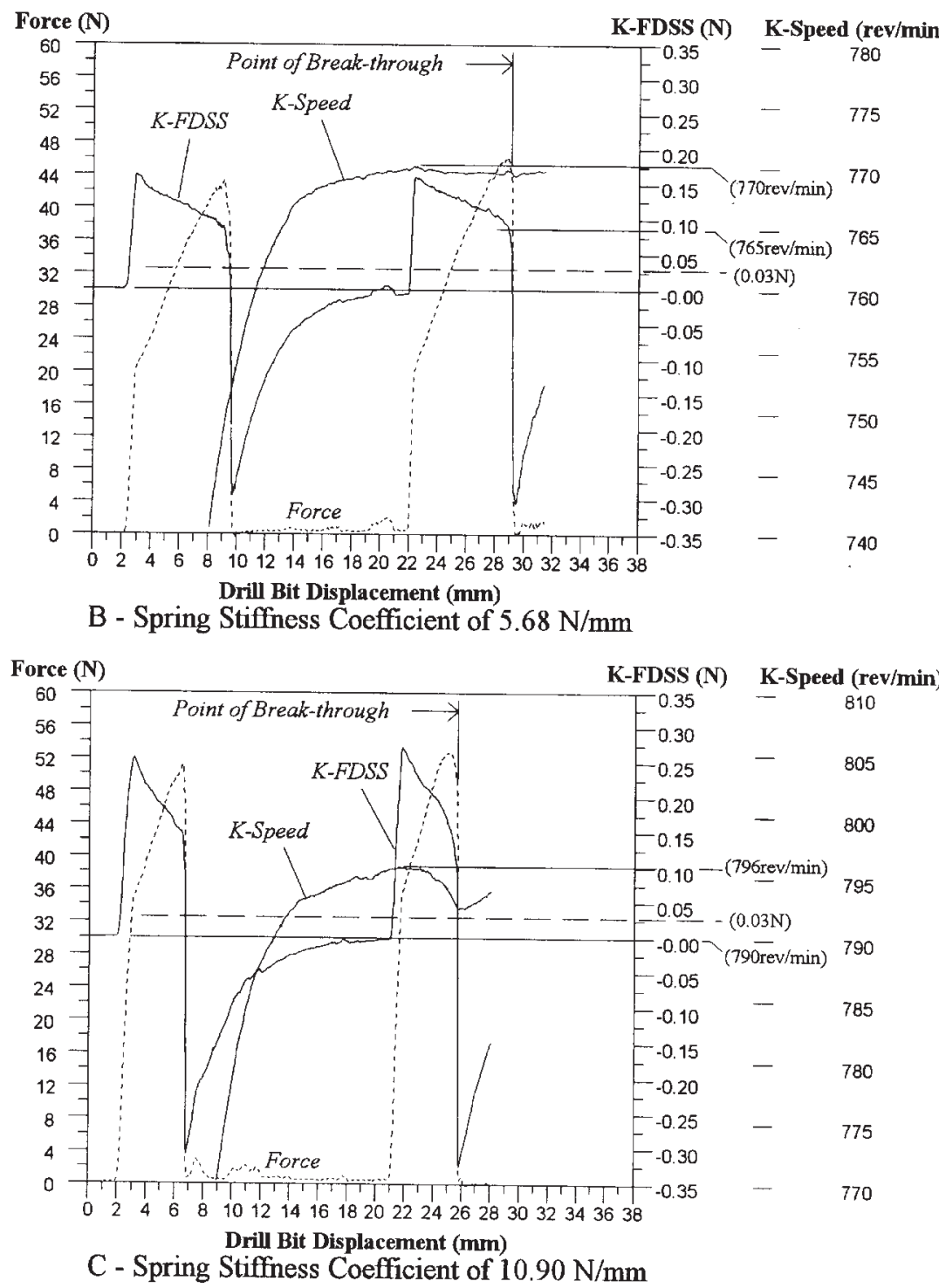

Fig. 10 Profiles of drilling force, processed Kalman FDSS (K-FDSS) and processed Kalman rotational speed (K-Speed) for a porcine femoral shaft with system compliance (feed rate $=90 \mathrm{~mm} / \mathrm{min}$; rated speed $=1000 \mathrm{r} / \mathrm{min})$ 


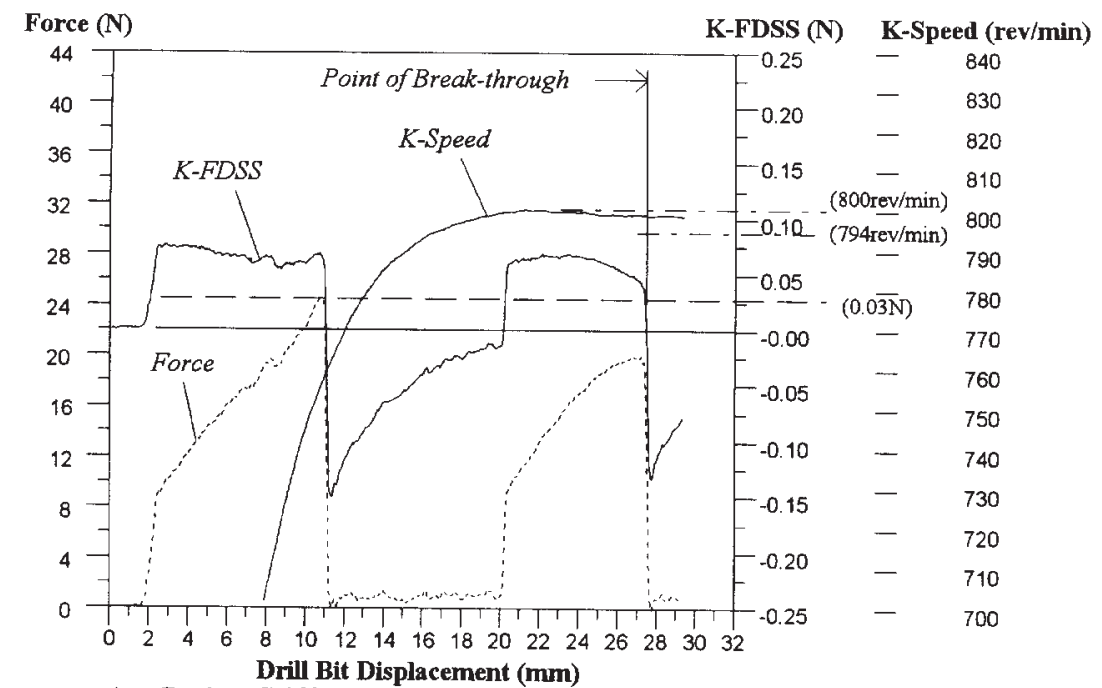

A - Spring Stiffness Coefficient of $2.80 \mathrm{~N} / \mathrm{mm}$

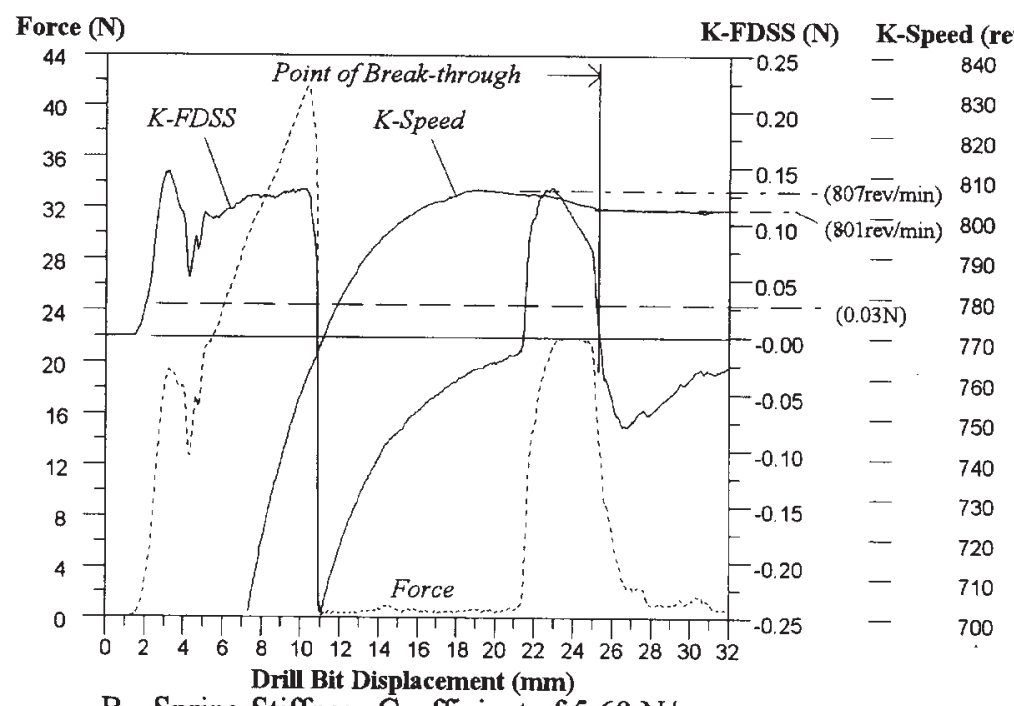

B - Spring Stiffness Coefficient of $5.68 \mathrm{~N} / \mathrm{mm}$

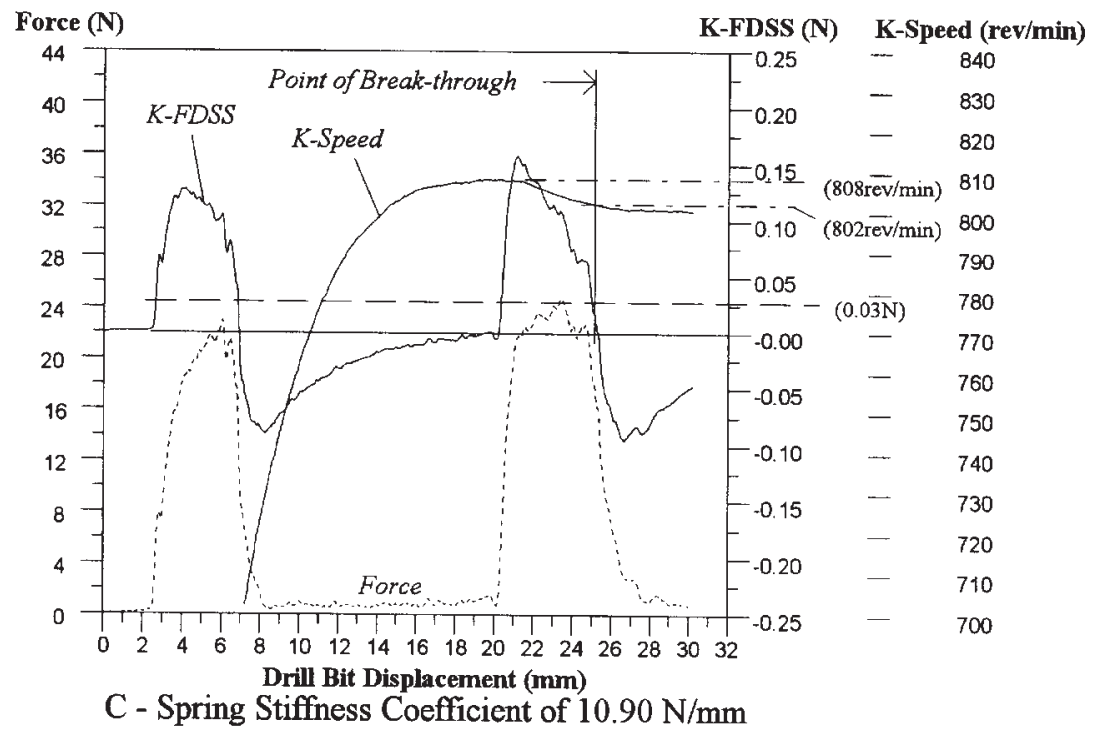

Fig. 11 Profiles of drilling force, processed Kalman FDSS (K-FDSS) and processed Kalman rotational speed (K-Speed) for a porcine femoral shaft with system compliance using a surgical drill bit (feed rate $=90 \mathrm{~mm} / \mathrm{min}$; rated speed $=1000 \mathrm{r} / \mathrm{min}$ ) 


\section{REFERENCES}

1 Müller, M. E., Allgöwer, M., Schneider, R. and Willenegger, H. Manual of Internal Fixation-Techniques Recommended by the AO-ASIF Group, 3rd edition, 1991 (Springer-Verlag, Berlin).

2 Brett, P. N., Baker, D. A., Reyes, L. and Blanshard, J. An automatic technique for micro-drilling a stapedotomy in the flexible stapes footplate. Proc. Instn Mech. Engrs, Part H, Journal of Engineering in Medicine, 1995, 209(H4), 255-262.

3 Allotta, B., Belmonte, F., Bosio, L. and Dario, P. A mechatronic tool for drilling in orthopaedics. In Proceedings of the 2nd International Workshop on Mechatronics in Medicine and Surgery, 1995, pp. 92-107.

4 Hutchings, H. Interfacing with C, 1995 (ButterworthHeinemann, Oxford).
5 Bouazza-Marouf, K., Browbank, I. and Hewit, J. R. Roboticassisted internal fixation of femoral fractures. Proc. Instn Mech. Engrs, Part H, Journal of Engineering in Medicine, 1995, 209(H1), 51-58.

6 Farnworth, G. H. and Burton, J. A. Optimization of drill geometry for orthopaedic surgery. In Proceedings of the 14th International Conference on Machine Tool Design and Research, 1974, paper 28, pp. 227-233.

7 Jacobs, C. H., Berry, J. T., Pope, M. H. and Hoaglund, F. T. A study of the bone machining process - drilling. J. Biomechanics, 1976, 9, 343-349.

8 Wiggins, K. L. and Malkins, S. Drilling of bone. J. Biomechanics, 1976, 9, 553-559.

9 Saha, S., Pal, S. and Albright, J. A. Surgical drilling: design and performance of an improved drill. Trans. ASME, J. Biomech. Engng, 1982, 104, 245-252. 